\title{
Gene mapping study for constitutive skin color in an isolated Mongolian population
}

\author{
Seung Hwan Paik ${ }^{1 *}$, Hyun-Jin Kim ${ }^{2,3 *}$, \\ Ho-Young Son ${ }^{4}$, Seungbok Lee, \\ Sun-Wha $\mathrm{Im}^{4}$, Young Seok $\mathrm{Ju}^{2,4}$, Je Ho Yeon ${ }^{1}$, \\ Seong Jin Jo ${ }^{1}$, Hee Chul Eun ${ }^{1,5,6}$, \\ Jeong-Sun Seo ${ }^{2,3,4}$, Oh Sang Kwon ${ }^{1,5,6,8}$ \\ and Jong-II Kim ${ }^{2,3,4,7,8}$ \\ ${ }^{1}$ Department of Dermatology \\ Seoul National University College of Medicine \\ ${ }^{2}$ Genomic Medicine Institute (GMI) \\ Medical Research Center \\ Seoul National University \\ ${ }^{3}$ Department of Biomedical Sciences \\ Seoul National University Graduate School \\ ${ }^{4}$ Department of Biochemistry and Molecular Biology \\ Seoul National University College of Medicine \\ Seoul 110-799, Korea \\ ${ }^{5}$ Laboratory of Cutaneous Aging and Hair Research \\ Clinical Research Institute \\ Seoul National University Hospital \\ Seoul 110-744, Korea \\ ${ }^{6}$ Institute of Dermatological Science \\ Seoul National University College of Medicine \\ ${ }^{7}$ Psoma Therapeutics, Inc. \\ Seoul 110-799, Korea \\ ${ }^{8}$ Corresponding authors: Tel, 82-2-740-8421; \\ Fax, 82-2-747-8250; E-mail, jongil @ snu.ac.kr (J.I.K.) \\ Tel, +82-2-2072-1996; Fax, +82-2-742-7344; \\ E-mail, oskwon@snu.ac.kr (O.S.K.) \\ *These authors contributed equally to this work. \\ http://dx.doi.org/10.3858/emm.2012.44.3.020 \\ Accepted 21 December 2011 \\ Available Online 26 December 2011
}

Abbreviations: GWAS, genome-wide association study; MI, melanin index; STR, short tandem repeat

\begin{abstract}
To elucidate the genes responsible for constitutive human skin color, we measured the extent of skin pigmentation in the buttock, representative of lifelong non-sun-exposed skin, and conducted a gene map-
\end{abstract}

ping study on skin color in an isolated Mongolian population composed of 344 individuals from 59 families who lived in Dashbalbar, Mongolia. The heritability of constitutive skin color was 0.82 , indicating significant genetic association on this trait. Through the linkage analysis using 1,039 short tandem repeat (STR) microsatellite markers, we identified a novel genomic region regulating constitutive skin color on 11q24.2 with an logarithm of odds (LOD) score of 3.39. In addition, we also found other candidate regions on 17q23.2, 6q25.1, and $13 q 33.2$ (LOD $\geq 2$ ). Family-based association tests on these regions with suggestive linkage peaks revealed ten and two significant single nucleotide polymorphisms (SNPs) on the linkage regions of chromosome 11 and 17 , respectively. We were able to discover four possible candidate genes that would be implicated to regulate human skin color: ETS1, UBASH3B, ASAM, and CLTC.

Keywords: genetic association studies; genetic linkage; microsatellite repeats; polymorphism, single nucleotide; quantitative trait, heritable; skin pigmentation

\section{Introduction}

The human skin color is one of the most perceptible phenotypic variations among humans and is known to be determined primarily by the amount and type of melanin which is synthesized within melanosomes in melanocytes (Thong et al., 2003). There is a high degree of variation in human skin color that ranges from dark brown to nearly colorless (Sturm, 2009).

Due to the advance of high-throughput SNPs genotyping technology, several genome-wide association studies (GWAS) for pigmentary traits (iris color, hair color, skin color, and tanning ability) have been conducted. To date, eleven genes have been identified to be related to pigmentation: TYR (11q14.3), TYRP1 (9P23), OCA2 (15q12-q13.1), SLC45A2 (5p13.2), SLC24A5 (15q21.1), MC1R (16q24.3), ASIP (20.q11.22), KITLG (12q21.32), SLC24A4 (14q32.12), IRF4 (6p25.3), and TPCN2 (11q13.3) (Stokowski et al., 2007; Sulem et al., 2007, 2008; Han et al., 2008; Kayser et al., 2008; 
Table 1. Basic characteristics of the pedigrees and the subjects

\begin{tabular}{clc}
\hline & & Value \\
\hline Pedigrees & No. of pedigrees & 59 \\
information & Mean (SD) of pedigree size & $11(5.9)$ \\
& Range of pedigree size & $3-33$ \\
& No. of pairs & \\
& Parent-offspring & 706 \\
& Sibling & 155 \\
& Sister-sister & 59 \\
& Brother-brother & 22 \\
& Brother-sister & 74 \\
& Half-sibling & 74 \\
& Grandparent-grandchild & 384 \\
& Avuncular & 175 \\
Subjects & Cousin & 69 \\
information & No. of subjects & 344 \\
& Mean (SD) of age & $30.4(16.8)$ \\
& Percentage female $(\%)$ & 57.8 \\
& No. of before puberty $(<13 \mathrm{yr})$ & 65 \\
& No. of after puberty $(\geq 13 \mathrm{yr})$ & 279 \\
& Mean (SD) of Ml & $282.4(122.3)$ \\
\hline
\end{tabular}

$\mathrm{SD}$, standard deviation; MI, melanin index.

Nan et al., 2009). From comparative genomics, we know that there are 378 loci (171 cloned genes and 207 uncloned genes) influencing pigmentation in mice and their human and zebrafish homologues available from the ESPCR web site (www.espcr.org/micemut/). However, only eleven genes are known to be related to human pigmentary traits, whereas hundreds of candidate genes have been found in mice. In addition, three of these eleven genes (SLC24A4 (14q32.12), IRF4 (6p25.3), and TPCN2 (11q13.3)) were recently newly identified in human GWAS that had not been known to be related to color variation in mice (Sturm, 2009). Therefore, there is possibility for the existence of as-yet-unidentified genetic loci and culprit genes associate with human pigmentary traits.

Most previously reported genes from those GWAS are mainly associated with general pigmentary traits. Considering that individuals with European ancestry show a higher degree of variation in eye and hair color compared to that in skin color (Rees, 2003; Sturm and Frudakis, 2004), the genes regulating skin color variation may differ from those of eye and hair color. Furthermore, most previous studies regarding skin color were so much as focused on tanning ability. Notably, the question of which genes are responsible for the variation of constitutive skin color among individuals is not still clearly answered. The only GWAS of constitutive skin color was conducted by Stokowski et al. who identified SLC24A5 (15q21.1), TYR (11q14.3), and SLC45A2 (5p13.2) as candidate genes (Stokowski et al., 2007). They measured skin color in six sites (both inner forearms, the outer forearms, and the inner arms above the elbows) and regarded the lightest skin color from those sites as constitutive skin color. To study exact constitutive skin color and further control for the confounding effect of sun exposure, we conducted a gene mapping study using objectively measured skin color in the buttock area, a prime example of lifelong lack of sun exposure.

Human skin color is a complex trait that is affected by the involvement of multiple genes. To identify genes regulating complex traits, isolated population models are most suitable because of decreased genetic heterogeneity and environmental variations. Thus, we selected an isolated population in rural Mongolia with identical ethnic backgrounds and life-styles.

In this study, we conducted a genome-wide linkage analysis of intrinsic skin color and further family-based association tests was used for fine

Table 2. Comparison between male and female according to puberty

\begin{tabular}{|c|c|c|c|c|}
\hline & Male & Female & Total & $P$ value ${ }^{*}$ \\
\hline \multicolumn{5}{|l|}{ No. of subjects } \\
\hline Before puberty $(<13 \mathrm{yr})$ & $33(50.8)$ & $32(49.2)$ & $65(100.0)$ & \\
\hline After puberty ( $\geq 13 \mathrm{yr}$ ) & $112(40.1)$ & 167 (59.9) & $279(100.0)$ & \\
\hline Total & $145(42.2)$ & $199(57.8)$ & $344(100.0)$ & \\
\hline \multicolumn{5}{|l|}{ Mean (SD) of Ml } \\
\hline Before puberty $(<13 \mathrm{yr})$ & $381.1(103.4)$ & $364.0(99.6)$ & $372.7(101.1)$ & 0.542 \\
\hline After puberty ( $\geq 13 \mathrm{yr}$ ) & $301.4(127.2)$ & $234.5(101.9)$ & $261.3(117.2)$ & $<0.0001$ \\
\hline Total & $319.5(126.4)$ & $255.3(111.9)$ & $282.4(122.3)$ & $<0.0001$ \\
\hline
\end{tabular}

$\mathrm{SD}$, standard deviation; MI, melanin index.

${ }^{*} P$ value for comparison between male and female was estimated by Kolmogorov-Smirnov Two-Sample Test since its distribution was not normally distributed. 
mapping under selected regions with highest linkage peaks.

\section{Results}

\section{Participant characteristics}

Table 1 shows basic descriptions of the pedigrees and the subjects. The pedigree data used for this study were comprised of 344 individuals from 59 families with 706 parent-offsprings, 155 siblings, 74 half-siblings, 384 grandparents-grandchild, 175 avunculars, and 69 cousins. The average pedigree size was 11 , ranging from 3 to 33 . The mean age of study subjects was $30.4 \mathrm{yr}$. The proportion of females $(n=199,57.8 \%)$ was higher than that of males $(n=145,42.2 \%)$.

MI (melanin index) has been used widely to indicate skin color objectively and is lower in individuals with lighter skin. We examined the $\mathrm{MI}$ in the buttock, which was representative of unexposed skin. The detailed results of MI according to sex and age are shown in Table 2. The mean MI in females $($ mean $=255.3, S D=111.9)$ was significantly lower than that in males (mean $=319.5, \mathrm{SD}=$ 126.4; $P$ value $<0.0001)$. To investigate the effect

Table 3. Intraclass correlations between family pairs and Heritability of $\mathrm{Ml}$

\begin{tabular}{lcc}
\hline \multicolumn{1}{c}{ Relationship } & $\begin{array}{c}\text { Intraclass correlation* } \\
\pm \text { SE }\end{array}$ & $P$ value \\
\hline Parent-offspring & $0.52 \pm 0.08$ & $<0.0001$ \\
Sibling & $0.38 \pm 0.11$ & 0.002 \\
Grandparent & $0.07 \pm 0.21$ & 0.738 \\
Avuncular & $0.13 \pm 0.13$ & 0.322 \\
Cousin & $0.05 \pm 0.16$ & 0.741 \\
Spouse & $-0.01 \pm 0.19$ & 0.971 \\
\hline Heritability ${ }^{*}, h^{2} \pm$ SE & $0.82 \pm 0.11$ & $<0.0001$ \\
\hline
\end{tabular}

$\mathrm{SE}$, standard error.

*Heritability and intraclass correlations were estimated as residual value after adjusting by significant covariates such as sex, age, and sex $\times$ age $^{2}$. of age on the sexual dimorphism of the skin color, we compared the results of subjects before $(<13$ $\mathrm{yr})$ and after puberty $(\geq 13 \mathrm{yr})$. The number of subjects before and after puberty was 65 and 279 , respectively. The mean $\mathrm{Ml}$ after puberty was decreased in both sexes. Before puberty, there was no sex difference in mean MI, whereas the mean $\mathrm{MI}$ of females after puberty was significantly lower than that of males $(P$ value $<0.0001)$.

\section{Familial correlations and heritability}

The familial correlations between family pairs and heritability of MI are shown in Table 3 . The familial correlation between parent and offspring was the largest (pair $r=0.52, S E=0.08)$ and significant $(P$ value $<0.0001)$. In addition, the correlation between siblings was also statistically significant $(P$ value $=$ 0.002 ). Notably, spouse correlations were not significant $(P$ value $=0.971)$. Also, the heritability for MI was very high and statistically significant $\left(h^{2}\right.$ $=0.82, \mathrm{SE}=0.11 ; P$ value $<0.0001)$. The above results suggest a strong evidence for and importance of genetic factors in controlling skin color.

\section{Linkage analysis}

On genome-wide multipoint linkage scanning, we found four suggestive regions with an logarithm of odds (LOD) score over 2 among 22 autosomes (Table 4 and Figure 1). It was previously proposed that there is significant evidence for linkage with an LOD score over 3.3 (Lander and Kruglyak, 1995). We discovered the locus of the highest LOD score of 3.39 on $11 \mathrm{q} 24.2$ at the required level of significance and in that region the nearest marker was D11S4151 (empirical $P$ value $<0.0001$ ). On chromosome 11, support linkage interval encompassing a 1.5 LOD score - maximum LOD score ranged from $123 \mathrm{cM}$ to $147 \mathrm{cM}$. Other candidate linkage regions were located on chromosome 17 with an LOD score of 3.03 (empirical $P$ value $=$ 0.0002 ), chromosome 6 with an LOD score of 2.76

Table 4. Results of genome-wide linkage scan for MI (LOD score > 2)

\begin{tabular}{|c|c|c|c|c|c|}
\hline $\begin{array}{c}\text { Chromosome } \\
\text { (location) }\end{array}$ & $\begin{array}{l}\text { Maximum } \\
\text { LOD score }\end{array}$ & $\begin{array}{c}\text { Nearest } \\
\text { marker }\end{array}$ & $\begin{array}{l}\text { Cytogenetic } \\
\text { region }\end{array}$ & Support interval* & $\begin{array}{c}\text { Empirical } \\
P \text { value }\end{array}$ \\
\hline $11(135)$ & 3.39 & D11S4151 & $11 q 24.2$ & $123 \mathrm{cM}-147 \mathrm{cM}$ & $<0.0001$ \\
\hline $17(92)$ & 3.03 & D17S794 & $17 q 23.2$ & 89 cM - 99 cM & 0.0002 \\
\hline $6(151)$ & 2.76 & D6S1687 & $6 q 25.1$ & $147 \mathrm{cM}-156 \mathrm{cM}$ & 0.0002 \\
\hline $13(102)$ & 2.27 & D13S797 & $13 q 33.2$ & $100 \mathrm{cM}-105 \mathrm{cM}$ & 0.0010 \\
\hline
\end{tabular}

LOD, logarithm of odds.

*Support interval is defined from maximum to 1.5 LOD score. 
A

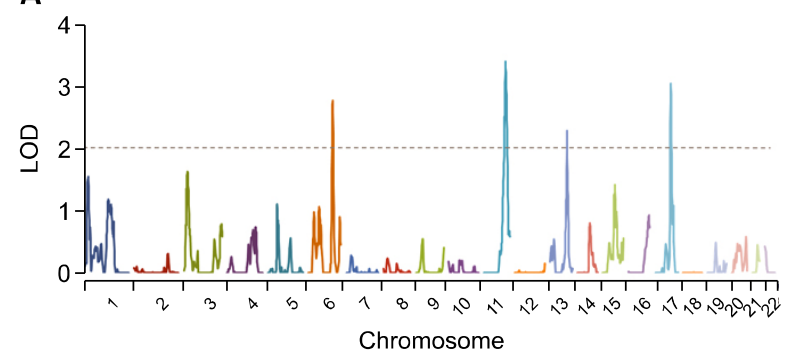

B

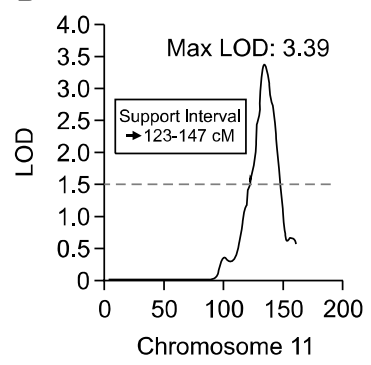

D

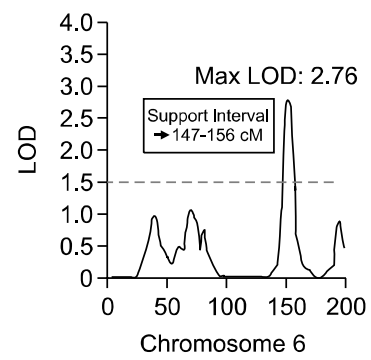

C

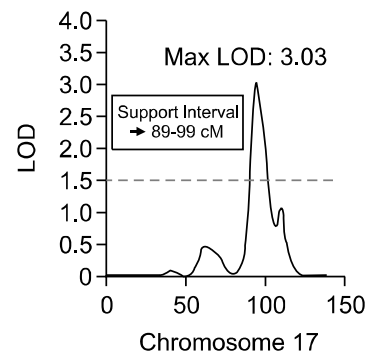

E

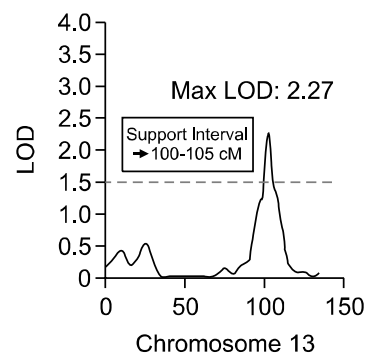

Figure 1. Genome-wide multipoint linkage analysis results for Ml across 22 autosomes (A), peak of linkage on chromosome $11(B)$, chromosome $17(\mathrm{C})$, chromosome $6(\mathrm{D})$, and chromosome $13(\mathrm{E})$.

(empirical $P$ value $=0.0002$ ), and chromosome 13 with an LOD score of 2.27 (empirical $P$ value $=$ 0.001 ), having the nearest marker (linkage support interval) of D17S794 (89-99 cM), D6S1687 (147-156 cM), and D13S797 (100-105 cM), respectively.

To disregard the differences in mean MI before and after puberty, we also carried out an additional linkage analysis with subjects after puberty. The linkage peaks on our four candidate regions were maintained, although the maximum LOD scores were slightly reduced (Data not shown).

\section{Family-based association test}

To test association in the presence of linkage, we conducted a family-based association study of MI under support linkage interval on those four candidate linkage regions (Figures 1B-1E). The null hypothesis of no association and linkage was used for fine mapping under a linkage peak. This method can be applied when using the same data set for testing linkage and association (Laird and Lange, 2006). Family-based association results under linkage peaks are shown in Table 5. On the linkage region of chromosome 11 , we identified ten significant SNPs reached at $P$ value $<1.0 \times 10^{-6}$, and six out of those ten significant SNPs were located within 3 candidate genes such as ETS1 (v-ets erythroblastosis virus E26 oncogene homolog 1 (avian)), UBASH3B (ubiquitin associated and $\mathrm{SH} 3$ domain containing, B), and ASAM (Adipocytespecific adhesion molecule). In addition, two significant SNPs were discovered on chromosome 17 and both of them were located within CLTC (clathrin, heavy chain $(\mathrm{Hc})$ ) gene, another candidate gene for regulating skin color. On chromosome 6

Table 5. Family-based association results between SNPs and MI under significant linkage regions

\begin{tabular}{|c|c|c|c|c|c|c|}
\hline $\mathrm{Chr}$ & SNP & Locus & Position* & Minor allele (MAF) & FBAT $P$ value & Gene \\
\hline 11 & rs4936890 & $11 q 24.1$ & $123,419,952$ & $\mathrm{G}(0.24)$ & $8.56 \times 10^{-9}$ & - \\
\hline 11 & rs7126621 & $11 \mathrm{q} 24.3$ & $127,951,397$ & $A(0.35)$ & $1.13 \times 10^{-8}$ & ETS1 \\
\hline 11 & rs10790522 & $11 q 24.1$ & $122,092,782$ & $C(0.45)$ & $1.77 \times 10^{-7}$ & UBASH3B \\
\hline 11 & rs10790521 & $11 q 24.1$ & $122,085,329$ & $\mathrm{G}(0.41)$ & $2.06 \times 10^{-7}$ & UBASH3B \\
\hline 11 & rs7947913 & $11 q 24.1$ & $123,423,666$ & $C(0.34)$ & $2.08 \times 10^{-7}$ & - \\
\hline 11 & rs555228 & $11 \mathrm{q} 24.2$ & $125,565,293$ & $A(0.19)$ & $3.56 \times 10^{-7}$ & - \\
\hline 11 & rs2187151 & $11 q 24.2$ & $123,952,011$ & $\mathrm{~T}(0.21)$ & $5.86 \times 10^{-7}$ & - \\
\hline 11 & rs11605822 & $11 q 24.1$ & $122,491,536$ & $A(0.21)$ & $5.93 \times 10^{-7}$ & $A S A M$ \\
\hline 11 & rs11607994 & $11 q 24.1$ & $122,491,682$ & $C(0.21)$ & $5.93 \times 10^{-7}$ & ASAM \\
\hline 11 & rs11218771 & $11 q 24.1$ & $122,093,794$ & $\mathrm{~T}(0.40)$ & $7.53 \times 10^{-7}$ & UBASH3B \\
\hline 17 & rs7224631 & $17 q 23.1$ & $55,087,696$ & $\mathrm{G}(0.39)$ & $9.74 \times 10^{-7}$ & CLTC \\
\hline 17 & rs10515171 & $17 q 23.1$ & $55,102,321$ & $A(0.39)$ & $9.74 \times 10^{-7}$ & CLTC \\
\hline
\end{tabular}

Chr, chromosome; FBAT, family based association test; MAF, minor allele frequency.

The 12 SNPs reached at significant $\left(P\right.$ value $\left.<1.0 \times 10^{-6}\right)$ are shown in Table 4 .

*Positions are based on Build 36 from NCBI. 
A

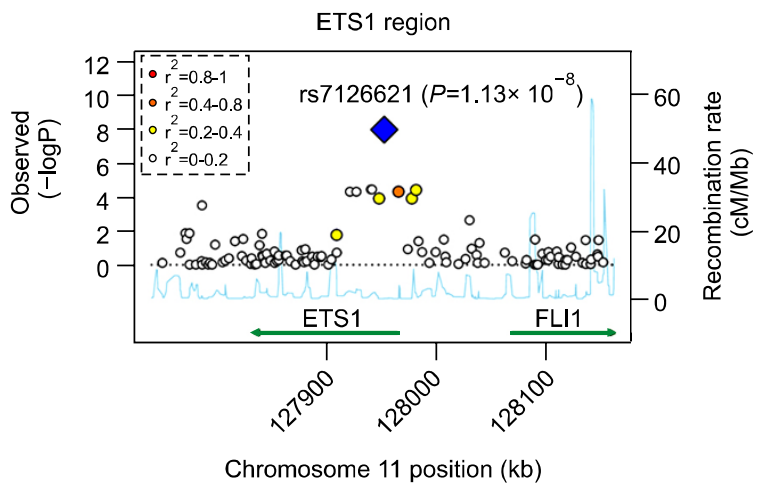

C

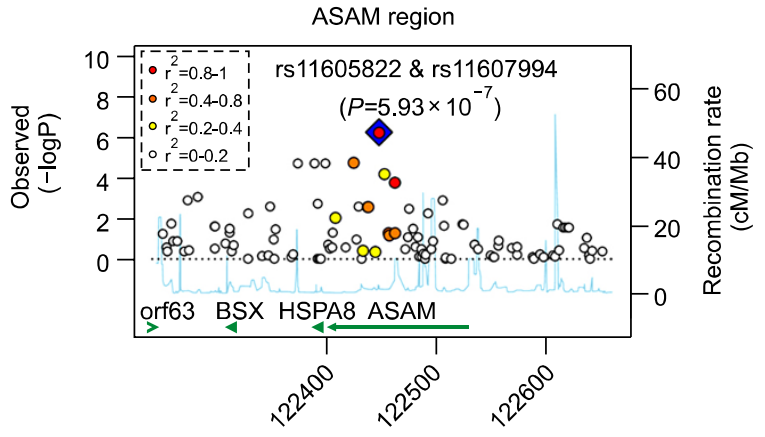

Chromosome 11 position (kb)
B

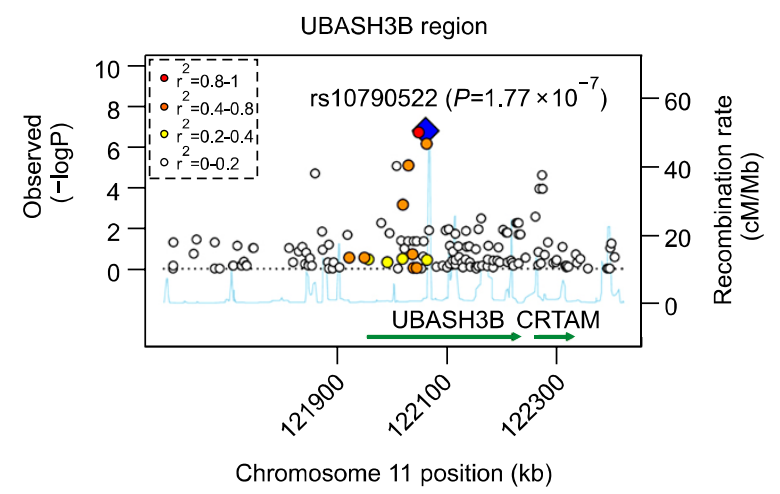

D

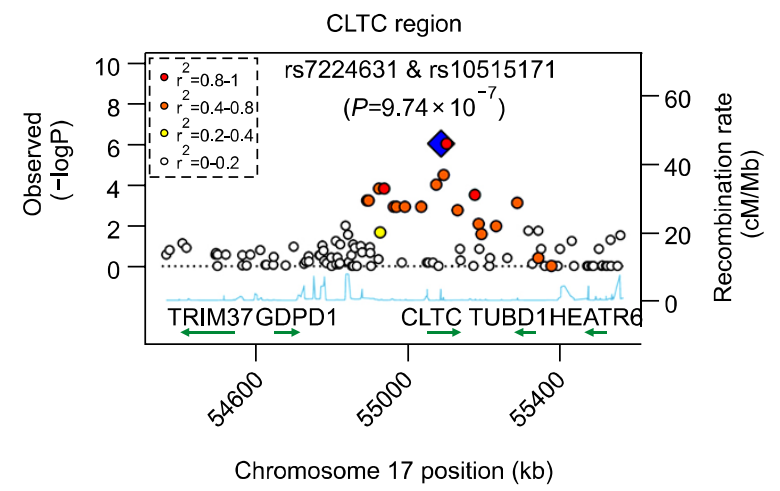

Figure 2. Regional association plot for ETS1 (A), UBASH3B (B), and ASAM (C) on chromosome 11 and CLTC (D) region on chromosome 17. The blue diamond indicates the strongest SNP in each gene region. The circle colors represent LD structure with the strongest $\operatorname{SNP}\left(r^{2}<0.2 ;\right.$ white, $0.2 \leq r^{2}<$ 0.4 ; yellow, $0.4 \leq r^{2}<0.8 ;$ orange, $r^{2} \geq 0.8 ;$ red).

and chromosome 13, we couldn't identify SNPs reached at $P$ value $<1.0 \times 10^{-6}$. These candidate genes are expressed in multiple tissues including skin (Supplemental Data Figure S1). Figure 2 shows regional association plot for the loci near the four candidate genes.

In addition, we carried out the replication study to confirm previously reported 11 genes associated with pigmentary traits: TYR (11q14.3), TYRP1 (9P23), OCA2 (15q12-q13.1), SLC45A2 (5p13.2), SLC24A5 (15q21.1), MC1R (16q24.3), ASIP (20.q11.22), KITLG (12q21.32), SLC24A4 (14q32.12), IRF4 (6p25.3), and TPCN2 (11q13.3). The results of association are shown in supplementary data Table S1. We couldn't find significant SNPs after adjusting multiple testing with stringent bonferroni correction. Therefore, we applied the less stringent criteria with significance level of $P$ value $\leq 1 \times$ $10^{-2}$. Of these 11 candidate genes, 5 genes were associated with MI (TYR, OCA2, SLC45A2, $S L C 24 A 4$, and IRF4). The lowest $P$ value in our results was found in OCA2 gene $(P$ value $=0.0018)$.

\section{Discussion}

Skin color is known to be related to age and sex. Sexual dimorphism in skin color has been reported, with females tending to have lighter skin color than males after puberty (Cartwright, 1975; Clark et al., 1981; Jaswal, 1983; Frost, 1988; Mehrai and Sunderland, 1990; Williams-Blangero and Blangero, 1991). Lightening of skin color is reported to occur during puberty in both sexes, but the process is less noticeable in males, so that females are lighter than males in adulthood (Mesa, 1983). In a recent study, the age of menarche in an Asian rural area, whose population has demographic features in common with our participants, was reported to be 12.8 (Rah et al., 2009). Therefore, we divided the participants into those younger and older than the age of 13, and analyzed the effect of puberty on skin color. Table 2 shows the MI of participants according to age and sex. Our data showed consistent results.

Familial correlation and heritability can be used 
widely as important indicators to understand genetic evidence of interesting traits prior to gene mapping study (Burton and Tobin, 2005). We found parent-offspring and sibling correlations for MI level to be strongest while spouse pair correlation, representative of the effects of environmental sharing, were not significant (Table 3). The pattern of significant correlations between closer familial relationships supports genetically important effects. In previous studies, high heritability of human skin color was reported, ranging from 0.55 to 0.83 (Clark et al., 1981; Frisancho et al., 1981). Our heritability value of 0.82 is comparable (Table 3 ).

Through genome-wide linkage analysis, we found four candidate regions associated with regulation of constitutive skin color (Table 4 and Figure 1). In family-based association study under regions of linkage on chromosomes $11,17,6$, and 13, we found twelve significant SNPs and four candidate genes (Table 5 and Figure 2). To the best of our knowledge, our linkage locus and significant SNPs were not previously reported to be related to the variation of human skin color.

Significant linkage evidence was observed on 11q24.2 with an LOD score of 3.39 and the second most statistically significant SNP (rs7126621) was located within the gene ETS1, which encodes Ets-1 transcription factor (Figure 2A). Target genes of Ets-1 include various matrix metalloproteinase and Ets-1 was reported to be related to the invasion of malignant melanoma (Rothhammer et al., 2004). Intriguingly, during early embryogenesis, Ets-1 is expressed in migrating neural crest cells which eventually differentiate into melanocytes (Meyer et al., 1997). The gene KITLG (KIT ligand) is also expressed in those cells and regulates migration from neural crest to skin and the association between polymorphisms within KITLG and pigmentations was previously reported (Sulem et al., 2007; Han et al., 2008). These data suggest that the genes regulating early migration of melanocyte progenitors could affect skin color and ETS1 could have a potential role in regulating skin pigmentation.

The third most significant SNP of the region (rs10790522) and other two significant SNPs (rs10790521 and rs11218771) were located within the gene UBASH3B (Figure 2B). The gene product of $U B A S H 3 B$ is regarded as being involved in the ubiquitination pathway. Interestingly, mice with null mutation in the gene MGRN1 (mahogunin, ring finger 1) which encodes E3 ubiquitin ligase show dark coat color and produce only eumelanin (dark, brown-black melanin) but not pheomelanin (light, red-yellow melanin) (He et al., 2003). Furthermore, ubiquitin-mediated proteasomal degradation plays important role in balance between synthesis and degradation of tyrosinase, the critical rate-limiting enzyme in melanin biosynthesis (Park et al., 2009). These data suggest that an abnormal ubiquitination pathway might be responsible for controlling constitutive skin color.

The both significant SNPs of rs 11605822 and rs11607994 were located within the ASAM gene, also known as CLMP (CXADR-like membrane protein) (Figure 2C). The gene product of ASAM is regarded as being involved in cell-to-cell adhesion and cell migration. This gene was reported to be expressed in malignant melanoma cells (Cheng et al., 2006). Therefore, as in case of ETS1, we think it could affect constitutive skin color through involving migration process of early melanocyte progenitors.

On 17q23.2, we found a candidate linkage region with an LOD score of 3.03. Both significant SNPs on that region (rs10515171 and rs7224631) were located within the gene CLTC (Figure 2D). CLTC gene encodes for a clathrin that is major protein component of intracellular organelles and functions in sorting cargo molecules in membrane traffic pathways. Clathrin is found in stage I melanosomes, melanocyte specific organelles in which synthesis, storage and transport of melanin take place (Wasmeier et al., 2008). A polymorphism in this gene would possibly alter trafficking of melanosomal protein and therefore could affect constitutive skin color.

In association study to verify previous reported genes associated with human pigmentary traits, we identified several replicated genes with moderate significance such as TYR, OCA2, SLC45A2, $S L C 24 A 4$, and IRF4. Although these genes showed moderate associations, OCA2 which is one of the most replicated candidate gene for pigmentary traits, had a lowest SNP $P$ value in this study. These data suggest that our results were extension of pre-existing studies of human pigmentary traits. However, we identified unique genes that have not been previously reported in relation to human skin color, showing much stronger association than known candidate genes. This uniqueness in our result may be explained by several reasons. Firstly, considering that most of the genes reported in past studies are associated with general pigmentary traits or tanning tendency and that this study was designed to examine constitutive skin color, the genes we have found appear to be responsible for only the genetically determined color of the skin. Secondly, our family based study designs may provide an opportunity for the discovery of as-yetunidentified genetic loci. Because unlike population based studies, family studies could detect the rare effects identified in specific families (Manolio et al., 
2009). Although replication study to validate our novel results remains, consistent results from our two gene mapping studies make this hypothesis reasonable. In addition, the family-based design strategy against population stratification makes our results robust.

In conclusion, on genome-wide multipoint linkage scanning, we found a novel genomic region regulating constitutive skin color on 11q24.2 with an LOD score of 3.39. In addition, we discovered other three candidate regions for controlling skin pigmentation: 17q23.2, 6q25.1 and 13q33.2. Further, family-based association test under support linkage regions revealed ten and two SNPs reached at significance level on linkage regions of chromosome 11 and 17, suggesting four possible candidate genes: ETS1, UBASH3B, ASAM, and CLTC. Our results could be used as a basis for further functional studies of melanocyte biology and may contribute to improve the current treatment of pigmentary skin diseases.

\section{Methods}

\section{Participants}

This study was conducted as part of the GENDISCAN (Gene Discovery for Complex traits in Asian population of Northeast area) project which is designed for the genetic mapping of complex traits in Asian populations (Im et al., 2009, 2010; Lee et al., 2009, 2010). A total of 750 individuals for skin pigmentation measurement were collected in Dashbalbar, Dornod Province, Mongolia. To increase power for detecting linkage, we selected 59 large pedigrees consisting of 344 individuals and genotyped them. The basic information containing pedigree relationship was confirmed by personal interviews, genotype data, and questionnaires. Informed consent was obtained from all recruited subjects, and our study protocol was approved by the institutional review board (IRB) of Seoul National University (approval number, $\mathrm{H}-0307-105-002)$. The study was conducted according to the Declaration of Helsinki Principles.

\section{Skin pigmentation measurement}

Skin pigmentation was measured with a Mexameter MX18 ${ }^{\circledR}$ (Courage and Khazaka, Köln, Germany). The measurement is based on the absorption principle. The probe of the Mexameter 18 emits light and a receiver measures the light reflected by the skin. The value of $\mathrm{MI}$ is calculated as the ratio of the quantity of light emitted from the probe and then absorbed by the skin and ranges from 0 to 999 . The site of measurement was the buttock area which was regarded as being representative of constitutive skin color.

\section{Genotyping}

Most of our protocols for genotyping were described previously (Ju et al., 2008; Kim et al., 2009). Briefly, leukocyte DNA was extracted by standard protocols. From all subjects, 1,039 short tandem repeat (STR) microsatellite markers were genotyped. We removed the Mendelian and non-Mendelian error markers. In addition, SNP markers in subsamples were also genotyped for family-based association study under linkage regions using the Illumina Human 610-Quad Beadchip. In quality control of SNPs, markers with low call rate $(<99 \%)$, high error rate $(>1 \%)$, and low MAF $(<0.01)$ were excluded. Chromosomes 11 , 17,6 , and 13 (maximum LOD score $>2$ ) were selected and in each chromosome, support linkage region was defined (ranging from 1.5 to maximum LOD unit). A total of 7,087 SNPs were used in these regions. Additively, we carried out the replication study for previously reported 11 genes associated with human pigmentation. We used the SNPs within $500 \mathrm{~kb}$ upstream and downstream of each gene. A total of 2,360 SNPs were used in this analysis.

\section{Statistical analysis}

Before genetic analysis, we evaluated the normal distribution of $\mathrm{MI}$ in the buttock. The distribution of Ml was right skewed (Kolmogorov-Smirnov $P$ value $<0.01$ ), and after log transformation, was normally distributed (KolmogorovSmirnov $P$ value $=0.13$ ). Basic statistical analysis was performed by SAS, version 9.1. We used covariate variables such as age, sex, age $\times$ sex, age ${ }^{2}$, age ${ }^{2} \times$ sex. We used the residual phenotypic variation of $\mathrm{Ml}$ for adjusting significant covariates with the screen option of Sequential Oligogenic Linkage Analysis Routines (SOLAR) package (Almasy and Blangero, 1998). To identify genetic evidence on MI, we estimated familial correlations and heritability. The FCOR option in Statistical Analysis for Genetic Epidemiology (S.A.G.E.), Release 6.0.1 (http://darwin. cwru.edu/) was used for estimating familial correlations (Keen and Elston, 2003). Narrow-sense heritability $\left(h^{2}\right)$ (proportion of phenotype variance attributable to additive genetic variance) was estimated with the variance component method in SOLAR. MIBD matrices were calculated using Markov chain Monte Carlo method with the Loki package. To localize the QTLs that influence MI, multipoint linkage analysis was performed using SOLAR. To estimate the empirical $P$ value, we performed 10,000 simulation replicates using the lodadj option in SOLAR. The PBAT tool in Helixtree software, version 6.4 (GoldenHelix Inc., Bozeman, MT) was used for family-based association testing. Based upon the "Linkage and no association (sandwich variance)" null hypothesis which can be used in the expanded pedigrees as it provides a robust variance estimate, we used FBAT-GEE (generalized estimating equation for FBAT) test statistic and an additive genetic model.

\section{Supplemental data}

Supplemental data include a figure and a table, and can be found with this article online at http://e-emm.or.kr/article/article_files/SP-44-3-07.pdf. 


\section{Acknowledgements}

We thank Lily Bae for the editing assistance of the manuscript and proofreading. This study was performed as a part of the GENDISCAN project that was approved and supported by the Korean Ministry of Education, Science and Technology (Grant Number \# M10305030002). This work was also supported by the second stage of the Brain Korea 21 Project and National Research Foundation of Korea (NRF) Grant funded by the Korean Government (MEST) (No. 2011-0001300).

\section{References}

Almasy L, Blangero J. Multipoint quantitative-trait linkage analysis in general pedigrees. Am J Hum Genet 1998;62: 1198-211

Burton PR, Tobin MD, Hopper JL. Key concepts in genetic epidemiology. Lancet 2005;366:941-51

Cartwright RA. Skin reflectance results from Holy Island, Northumberland. Ann Hum Biol 1975;2:347-54

Cheng SL, Huang Liu R, Sheu JN, Chen ST, Sinchaikul S, Tsay GJ. Toxicogenomics of kojic acid on gene expression profiling of a375 human malignant melanoma cells. Biol Pharm Bull 2006;29:655-69

Clark P, Stark AE, Walsh RJ, Jardine R, Martin NG. A twin study of skin reflectance. Ann Hum Biol 1981;8:529-41

Frisancho AR, Wainwright R, Way A. Heritability and components of phenotypic expression in skin reflectance of Mestizos from the Peruvian lowlands. Am J Phys Anthropol 1981;55:203-8

Frost P. Human skin color: a possible relationship between its sexual dimorphism and its social perception. Perspect Biol Med 1988;32:38-58

Han J, Kraft P, Nan H, Guo Q, Chen C, Qureshi A, Hankinson SE, Hu FB, Duffy DL, Zhao ZZ, Martin NG, Montgomery GW, Hayward NK, Thomas G, Hoover RN, Chanock S, Hunter DJ. A genome-wide association study identifies novel alleles associated with hair color and skin pigmentation. PLoS Genet 2008;4:e1000074

He L, Eldridge AG, Jackson PK, Gunn TM, Barsh GS. Accessory proteins for melanocortin signaling: attractin and mahogunin. Ann N Y Acad Sci 2003;994:288-98

Im SW, Lee MK, Lee HJ, Oh SI, Kim HL, Sung J, Cho SI, Seo JS, Kim JI. Analysis of genetic and non-genetic factors that affect the QTc interval in a Mongolian population: the GENDISCAN study. Exp Mol Med 2009;41:841-8

Im SW, Kim HJ, Lee MK, Yi JH, Jargal G, Sung J, Cho SI, Kim $\mathrm{JI}$. Genome-wide linkage analysis for ocular and nasal anthropometric traits in a Mongolian population. Exp Mol Med 2010;42:799-804

Jaswal IJ. Pigmentary variation in Indian populations. Acta Anthropogenet 1983;7:75-83

Ju YS, Park H, Lee MK, Kim JI, Sung J, Cho SI, Seo JS. A genome-wide Asian genetic map and ethnic comparison: the GENDISCAN study. BMC Genomics 2008;9:554
Kayser M, Liu F, Janssens AC, Rivadeneira F, Lao O, van Duijn K, Vermeulen M, Arp P, Jhamai MM, van ljcken WF, den Dunnen JT, Heath S, Zelenika D, Despriet DD, Klaver CC, Vingerling JR, de Jong PT, Hofman A, Aulchenko YS, Uitterlinden AG, Oostra BA, van Duijn CM. Three genome-wide association studies and a linkage analysis identify HERC2 as a human iris color gene. Am J Hum Genet 2008;82:411-23

Keen KJ, Elston RC. Robust asymptotic sampling theory for correlations in pedigrees. Stat Med 2003;22:3229-47

Kim JI, Ju YS, Park H, Kim S, Lee S, Yi JH, Mudge J, Miller NA, Hong D, Bell CJ, Kim HS, Chung IS, Lee WC, Lee JS, Seo SH, Yun JY, Woo HN, Lee H, Suh D, Kim HJ, Yavartanoo M, Kwak M, Zheng Y, Lee MK, Kim JY, Gokcumen O, Mills RE, Zaranek AW, Thakuria J, Wu X, Kim RW, Huntley JJ, Luo S, Schroth GP, Wu TD, Kim H, Yang KS, Park WY, Church GM, Lee C, Kingsmore SF, Seo JS. A highly annotated whole-genome sequence of a Korean individual. Nature 2009;460:1011-5

Laird NM, Lange C. Family-based designs in the age of large-scale gene-association studies. Nat Rev Genet 2006; 7:385-94

Lander E, Kruglyak L. Genetic dissection of complex traits: guidelines for interpreting and reporting linkage results. Nat Genet 1995;11:241-7

Lee JE, Park H, Ju YS, Kwak M, Kim JI, Oh HY, Seo JS. Higher mitochondrial DNA copy number is associated with lower prevalence of microalbuminuria. Exp Mol Med 2009;41: 253-8

Lee MK, Woo SJ, Kim JI, Cho SI, Kim H, Sung J, Seo JS, Kim DM. Replication of a glaucoma candidate gene on $5 q 22.1$ for intraocular pressure in mongolian populations: the GENDISCAN Project. Invest Ophthalmol Vis Sci 2010;51: $1335-40$

Manolio TA, Collins FS, Cox NJ, Goldstein DB, Hindorff LA, Hunter DJ, McCarthy MI, Ramos EM, Cardon LR, Chakravarti A, Cho JH, Guttmacher AE, Kong A, Kruglyak L, Mardis E, Rotimi CN, Slatkin M, Valle D, Whittemore AS, Boehnke M, Clark AG, Eichler EE, Gibson G, Haines JL, Mackay TF, McCarroll SA, Visscher PM. Finding the missing heritability of complex diseases. Nature 2009;461:747-53

Mehrai $H$, Sunderland E. Skin colour data from Nowshahr City, northern Iran. Ann Hum Biol 1990;17:115-20

Mesa MS. Analyse de la variabilite de la pigmentation de la peau durant la croissance. Bull M m Soc Anthropol Paris13 1983;10:49-60

Meyer D, Durliat M, Senan F, Wolff M, Andre M, Hourdry J, Remy P. Ets-1 and Ets-2 proto-oncogenes exhibit differential and restricted expression patterns during Xenopus laevis oogenesis and embryogenesis. Int J Dev Biol 1997;41: $607-20$

Nan H, Kraft P, Qureshi AA, Guo Q, Chen C, Hankinson SE, Hu FB, Thomas G, Hoover RN, Chanock S, Hunter DJ, Han $\mathrm{J}$. Genome-wide association study of tanning phenotype in a population of European ancestry. J Invest Dermatol 2009; 129:2250-7

Park SH, Kim DS, Lee HK, Kwon SB, Lee S, Ryoo IJ, Kim WG, Yoo ID, Park KC. Long-term suppression of tyrosinase by 
terrein via tyrosinase degradation and its decreased expression. Exp Dermatol 2009;18:562-6

Rah JH, Shamim AA, Arju UT, Labrique AB, Rashid M, Christian P. Age of onset, nutritional determinants, and seasonal variations in menarche in rural Bangladesh. $J$ Health Popul Nutr 2009;27:802-7

Rees JL. Genetics of hair and skin color. Annu Rev Genet 2003;37:67-90

Rothhammer T, Hahne JC, Florin A, Poser I, Soncin F, Wernert N, Bosserhoff AK. The Ets-1 transcription factor is involved in the development and invasion of malignant melanoma. Cell Mol Life Sci 2004;61:118-28

Stokowski RP, Pant PV, Dadd T, Fereday A, Hinds DA Jarman C, Filsell W, Ginger RS, Green MR, van der Ouderaa FJ, Cox DR. A genomewide association study of skin pigmentation in a South Asian population. Am J Hum Genet 2007;81:1119-32

Sturm RA, Frudakis TN. Eye colour: portals into pigmentation genes and ancestry. Trends Genet 2004;20:327-32

Sturm RA. Molecular genetics of human pigmentation diversity. Hum Mol Genet 2009;18:R9-17

Sulem P, Gudbjartsson DF, Stacey SN, Helgason A, Rafnar
T, Magnusson KP, Manolescu A, Karason A, Palsson A, Thorleifsson G, Jakobsdottir M, Steinberg S, Palsson S, Jonasson F, Sigurgeirsson B, Thorisdottir K, Ragnarsson R, Benediktsdottir KR, Aben KK, Kiemeney LA, Olafsson JH, Gulcher J, Kong A, Thorsteinsdottir U, Stefansson K. Genetic determinants of hair, eye and skin pigmentation in Europeans. Nat Genet 2007;39:1443-52

Sulem P, Gudbjartsson DF, Stacey SN, Helgason A, Rafnar T, Jakobsdottir M, Steinberg S, Gudjonsson SA, Palsson A, Thorleifsson G, Palsson S, Sigurgeirsson B, Thorisdottir K, Ragnarsson R, Benediktsdottir KR, Aben KK, Vermeulen $\mathrm{SH}$, Goldstein AM, Tucker MA, Kiemeney LA, Olafsson JH, Gulcher J, Kong A, Thorsteinsdottir U, Stefansson K. Two newly identified genetic determinants of pigmentation in Europeans. Nat Genet 2008;40:835-7

Thong HY, Jee SH, Sun CC, Boissy RE. The patterns of melanosome distribution in keratinocytes of human skin as one determining factor of skin colour. $\mathrm{Br} \mathrm{J}$ Dermatol 2003;149:498-505

Wasmeier C, Hume AN, Bolasco G, Seabra MC. Melanosomes at a glance. J Cell Sci 2008;121:3995-9

Williams-Blangero S, Blangero J. Skin color variation in eastern Nepal. Am J Phys Anthropol 1991;85:281-91 